\title{
TEMPERATURE DEPENDENCE OF ${ }^{57} \mathrm{Fe}$-MÖSSBAUER SPECTRA FOR A $F e_{F c}^{I I}-F e_{t p y}^{I I}-F e_{F c}^{I I}$ TRINUCLEAR SYSTEM
}

\author{
Dumitru Sirbu
}

\begin{abstract}
Institute of Chemistry of Academy of Sciences of Moldova, 3, Academiei str., Chisinau MD-2028, Republic of Moldova e-mail: sirbudyma@gmail.com,tel. (+373 22) 7397 22,fax (+373 22) 739954
\end{abstract}

\begin{abstract}
Fe}$ Mössbauer spectra were recorded for 1'-terpyridine ferrocenecarboxylic acid and [bis(1'-terpyridine ferrocenecarboxylic acid) $\mathrm{Fe}(\mathrm{II})]^{2+}$ in the temperature range $7-293 \mathrm{~K}$. The temperature dependence of the Quadrupole Splitting, Isomer Shift and Debye-Waller factor are discussed. The Debye temperature for the iron nuclei in the investigated compounds was determined.
\end{abstract}

Keywords: ferrocene, terpyridine, Mössbauer, Debye temperature.

Received: August 2014/ Revised final: September 2014/ Accepted: September 2014

\section{Introduction}

Mössbauer spectroscopy is a powerful tool for the study of various elements, especially for ${ }^{57} \mathrm{Fe}[1]$. Its main hyperfine interaction parameters are the Isomer Shift (IS), Quadrupole Splitting (QS) and magnetic hyperfine interaction. While the first one depends on the total electron density on the examined nucleus (mainly s orbitals), the second is a measure of the electric field gradient. Using these parameters a comprehensive description of the studied atom can be made (e.g. the oxidation state, spin state, changes in symmetry). The temperature dependence of the Debye-Waller factor of the Mössbauer Spectra (MS) gives information on the vibration of atom in the molecule and of molecule in the crystal. The Debye temperature, , can be determined and used for comparison of forces that bind an atom in the molecule [2].

We have previously described [3] the synthesis of 1'-terpyridine ferrocenecarboxylic acid FcT (Figure 1) from the asymmetrical 1'-formyl-ferrocenecarboxylic, as a ligand with an anchoring group to semiconductor surfaces (e.g. NiO). Surprisingly it underwent a light induced decomposition as result of ferrocene "sandwich" destruction and formation of the iron (II) bis-terpyridine $\left[\mathrm{Fe}(\mathrm{tpy})_{2}\right]^{2+}$ complex. The [bis(1'-terpyridine ferrocenecarboxylic acid) $\mathrm{Fe}(\mathrm{II})]^{2+}$ complex FeFcT (Figure 1) was isolated and its crystalline structure described [3]. Herein we describe the ${ }^{57} \mathrm{Fe}$ Mössbauer study of this $\boldsymbol{F} \boldsymbol{e}_{\boldsymbol{F} \boldsymbol{c}}^{I I}-\boldsymbol{F} \boldsymbol{e}_{\boldsymbol{t} \boldsymbol{I} \boldsymbol{I}}^{\boldsymbol{I I}}-\boldsymbol{F} \boldsymbol{e}_{\boldsymbol{F c}}^{I I}$ trinuclear system.

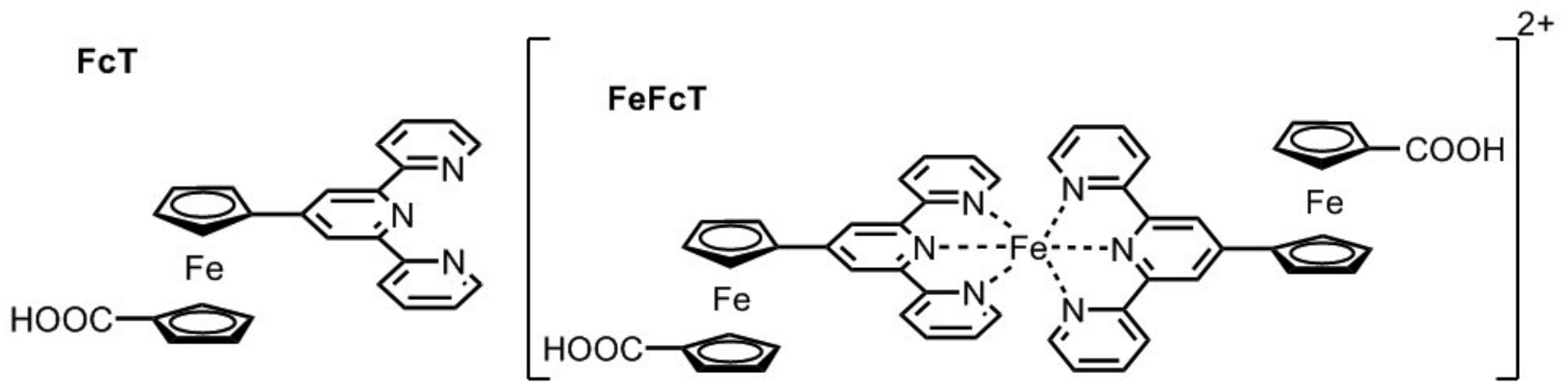

Figure 1. The molecular structures of FcT and FeFcT.

\section{Experimental}

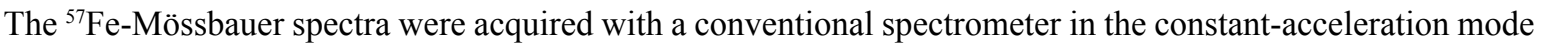
(MS4, Edina, USA) equipped with a ${ }^{57} \mathrm{Co}$ source in a rhodium matrix. Variable temperature Mössbauer experiments were done using closed cycle He gas refrigerator cryostat and a dual channel temperature controller SeeCo Model 106. Isomer shifts are given relative to $\alpha$-Fe at RT. The spectrum was fitted using the Mössbauer Spectral Analysis Software WMOSS4 Version F. The error limits for the each experimental point in the MS is $\pm 0.02 \mathrm{~mm} / \mathrm{s}$ on X-axis and less than $0.5 \%$ on Y-axis. All spectra were fitted for a lowest value, $<0.60$ for FcT and $<0.75$ for FeFcT. The linearity of plots was checked by use of $\mathrm{R}^{2}$ factor and respective error limits were determined.

\section{Synthesis}

Ferrocene was purchased from Sigma-Aldrich and used as received. Compounds FcT and FeFcT were prepared as we described previously [3].

\section{Results and discussion}

The MS for FcT and FeFcT are shown in Figure 2 with relevant parameters presented in Table 1. The room temperature MS for FCT is typical for a ferrocene derivative and consists of a large and clear doublet. The IS value of 
$0.43 \mathrm{~mm} / \mathrm{s}$ is similar (within the error limits) to the parent ferrocene, while the QS decreased by $0.22 \mathrm{~mm} / \mathrm{s}$. This is a result of the electron withdrawing effect of the carboxylic substituent which increase the symmetry of the electron environment on the iron nucleus, by removing electron density from the cyclopentadienide ring and consequently from Fe $d_{z 2}, d_{x z}, d_{y z}$ orbitals. The QS is even lower than for ferrocene-carboxylic acid [4], which suggest an additional effect of the terpyridine group. A similar effect was reported for the ferrocene diketones [5] and confirmed by Density Functional Theory, DFT, calculations [2]. The spectrum of FeFcT comprises two partially overlapped doublets attributed to the two carboxy-ferrocenes and [ $\left.\mathrm{Fe}(\mathrm{tpy})_{2}\right]^{2+}$ components, with parameters consistent with the literature data [6,7]. All $\mathrm{Fe}$ nuclei are low-spin $(\mathrm{S}=0)$ iron $\left(\mathrm{d}^{6}\right)$, but a more symmetrical pseudo-octahedral $\mathrm{N}_{6}$ coordination results in a lower QS for $\left[\mathrm{Fe}(\mathrm{tpy})_{2}\right]^{2+}$ compared to ferrocene. Decrease of the QS could be expected for ferrocene in FeFcT compared to FCT as result of terpyridine-to- $\mathrm{Fe}^{\mathrm{II}}$ electron pair donation but experimentally a slightly higher $(+0.04 \mathrm{~mm} / \mathrm{s})$ QS is observed. An explanation for this is the well-known for [ $\left.\mathrm{Fe}(\mathrm{tpy})_{2}\right]^{2+}$ metal-to-ligand back donation [8], which is partially compensating the electron density on terpyridines and consequently on cyclopentadienide rings. However, the "bowing" of the terpyridine ring upon complexation should be taken into account too.

The temperature dependence of Mössbauer spectra parameters is resulting in a number of observed changes. With decreasing the temperature a strong increase of the absorption for the $\mathrm{Fc}$ was observed, less pronounced for the $\left[\mathrm{Fe}(\mathrm{tpy})_{2}\right]^{2+}$ nucleus.

Table 1

Experimental Mössbauer parameters for FcT, FeFcT and reference compounds.

\begin{tabular}{|c|c|c|c|c|}
\hline Compound & Temperature, $K$ & $\begin{array}{l}\text { Isomer Shift", } \\
\quad \delta, \mathrm{mm} / \mathrm{s}\end{array}$ & $\begin{array}{c}\text { Quadrupole Splitting*, } \\
\qquad E_{Q}, \mathrm{~mm} / \mathrm{s}\end{array}$ & $\begin{array}{c}\text { Relative } \\
\text { Absorption } f_{T}^{\prime} / f_{7 K}^{\prime}\end{array}$ \\
\hline \multirow{9}{*}{ tu } & 7 & 0.53 & 2.18 & 1.00 \\
\hline & 40 & 0.53 & 2.18 & 0.97 \\
\hline & 80 & 0.53 & 2.17 & 0.90 \\
\hline & 120 & 0.52 & 2.18 & 0.83 \\
\hline & 150 & 0.50 & 2.18 & 0.76 \\
\hline & 180 & 0.50 & 2.17 & 0.63 \\
\hline & 200 & 0.49 & 2.18 & 0.59 \\
\hline & 250 & 0.46 & 2.17 & 0.46 \\
\hline & 297 & 0.43 & 2.17 & 0.30 \\
\hline \multirow{9}{*}{ 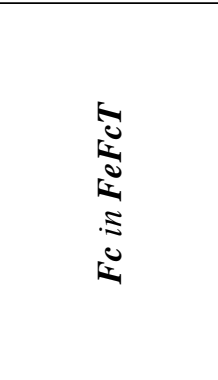 } & 7 & 0.55 & 2.22 & 1.00 \\
\hline & 40 & 0.54 & 2.22 & 0.94 \\
\hline & 80 & 0.53 & 2.23 & 0.82 \\
\hline & 120 & 0.52 & 2.22 & 0.73 \\
\hline & 150 & 0.51 & 2.22 & 0.64 \\
\hline & 180 & 0.50 & 2.23 & 0.58 \\
\hline & 200 & 0.49 & 2.22 & 0.50 \\
\hline & 250 & 0.46 & 2.22 & 0.36 \\
\hline & 293 & 0.44 & 2.21 & 0.20 \\
\hline \multirow{9}{*}{ 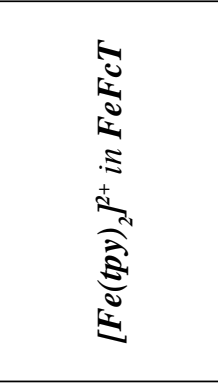 } & 7 & 0.27 & 1.10 & 1.00 \\
\hline & 40 & 0.27 & 1.08 & 0.99 \\
\hline & 80 & 0.27 & 1.07 & 0.97 \\
\hline & 120 & 0.27 & 1.06 & 0.98 \\
\hline & 150 & 0.27 & 1.05 & 0.91 \\
\hline & 180 & 0.26 & 1.05 & 0.85 \\
\hline & 200 & 0.25 & 1.06 & 0.76 \\
\hline & 250 & 0.23 & 1.05 & 0.66 \\
\hline & 293 & 0.21 & 1.05 & 0.38 \\
\hline \multirow{6}{*}{ 饪 } & 7 & 0.54 & 2.40 & 1.00 \\
\hline & 80 & 0.53 & 2.39 & 0.93 \\
\hline & 120 & 0.52 & 2.40 & 0.79 \\
\hline & 160 & 0.51 & 2.41 & 0.66 \\
\hline & 200 & 0.50 & 2.40 & 0.54 \\
\hline & 293 & 0.45 & 2.39 & 0.31 \\
\hline$\left[\mathrm{Fe}(t p y)_{2}\right]^{2+* *}$ & 80 & 0.28 & 1.05 & $\mathrm{n} / \mathrm{a}$ \\
\hline $\mathrm{FC}-\mathrm{COOH}^{* * *}$ & 293 & 0.53 & 2.21 & $\mathrm{n} / \mathrm{a}$ \\
\hline
\end{tabular}

${ }^{*}$ the error for values of IS and QS is $\pm 0.02 \mathrm{~mm} / \mathrm{s}$.

**** Data taken from references [6] and [4], respectively. 

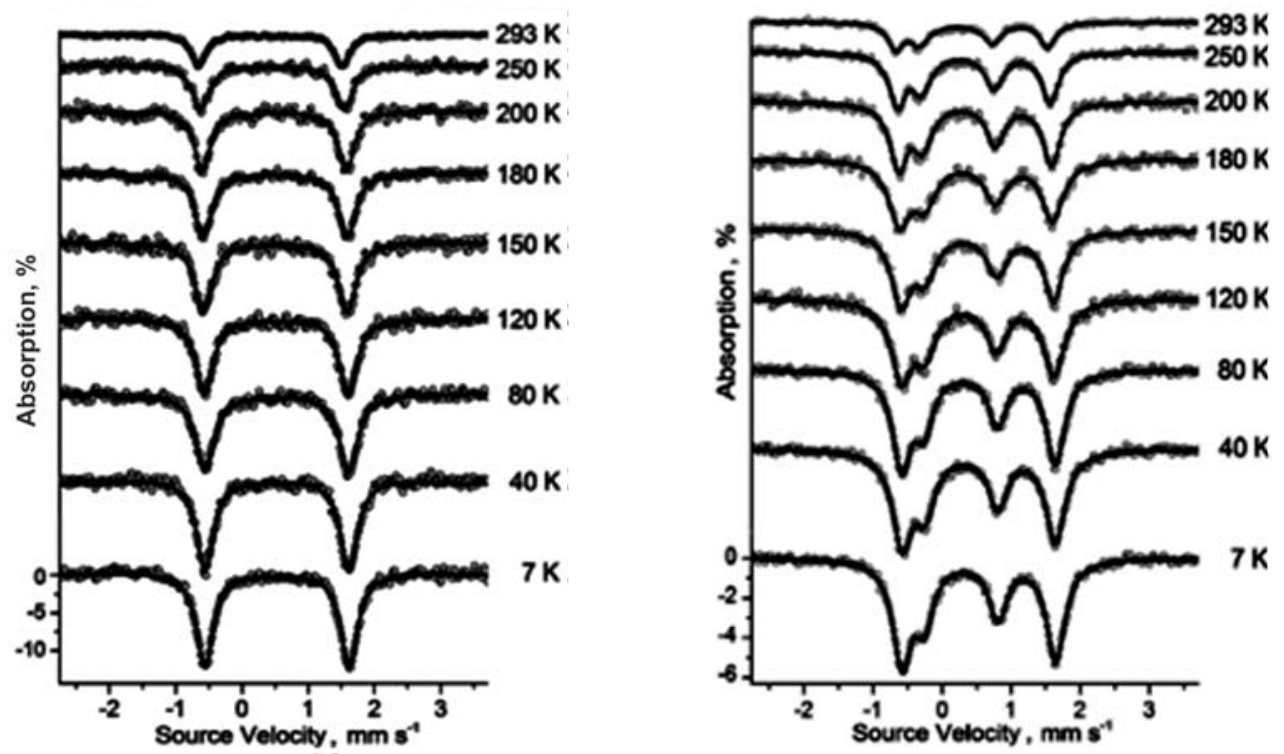

Figure 2. The Mössbauer spectra for FcT (left) and FeFcT (right) over 7 - $293 \mathrm{~K}$ temperature range.

The effect of the increase of recoil free fraction with decreasing the temperature was previously explained as the result of vibration diminution for the examined atom in the crystal lattice. The logarithmic form of the relation between recoil free absorption $f$ ' of the $\gamma$ rays and temperature $T$ for a "thin" absorber is given by Eq.(1) [9].

$\ln f^{\prime}=-\frac{6 E_{r}}{k \theta_{D}^{2}}$, where $T>\frac{\theta_{D}}{2}$

were $E_{r}$ is the recoil energy, $k$ is Boltzmann's constant. Plots of $\ln f^{\prime}$ versus $T$ allow us to calculate the Debye temperature from the slope of the line $\Delta\left(\ln f^{\prime}\right) / \Delta T$. The $f_{T}^{\prime} /_{f_{7 K}^{\prime}}=k_{e f f} \times A_{T} /_{k_{e f f} \times A_{7 K}}=A_{T} /_{A_{7 K}}$ can be used instead of $f^{\prime}$, where A is the experimentally determined area of peak and $k_{e f f}$ is an effective constant which take into consideration the experimental conditions (sample and equipment). The plot of $\ln f_{T}^{\prime} / f_{7 K}^{\prime}$ versus $T$ (Figure 3 ) for FcT is linear over the temperature range $80 \mathrm{~K}$ to $200 \mathrm{~K}$ and has a slope $\frac{6 E_{r}}{k \theta_{D}^{2}}=(4.0 \pm 0.3) \times 10^{-3}$ which corresponds to $\theta_{D}=(184 \pm 14) \mathrm{K}$. This value is somehow higher compared to that of parent ferrocene $\theta_{D}=(173 \pm 10) \mathrm{K}$. For the FeFcT two linear regressions with the slopes of $(4.2 \pm 0.4) \times 10^{-3}$ and $(2.9 \pm 0.2) \times 10^{-3}$ were obtained for $\mathrm{Fc}$ and $\left[\mathrm{Fe}(\text { tpy })_{2}\right]^{2+}$ nuclei, which give $\theta_{D}=(180 \pm 17) \mathrm{K}$ and $\theta_{D}=(218 \pm 15) \mathrm{K}$. The higher Debye temperature for the latter is suggesting a more rigid $\mathrm{N}_{6}$ bonding of $\mathrm{Fe}$ atom by two terpyridine molecules compared to the ferrocene "sandwich". This is a reasonable result taking in account the well-known stability of the $\left[\mathrm{Fe}(\text { tpy })_{2}\right]^{2+}$ complexes [10] and is in perfect accordance with the instability of ferrocene derivatives in the presence of terpyridine ligand [3].
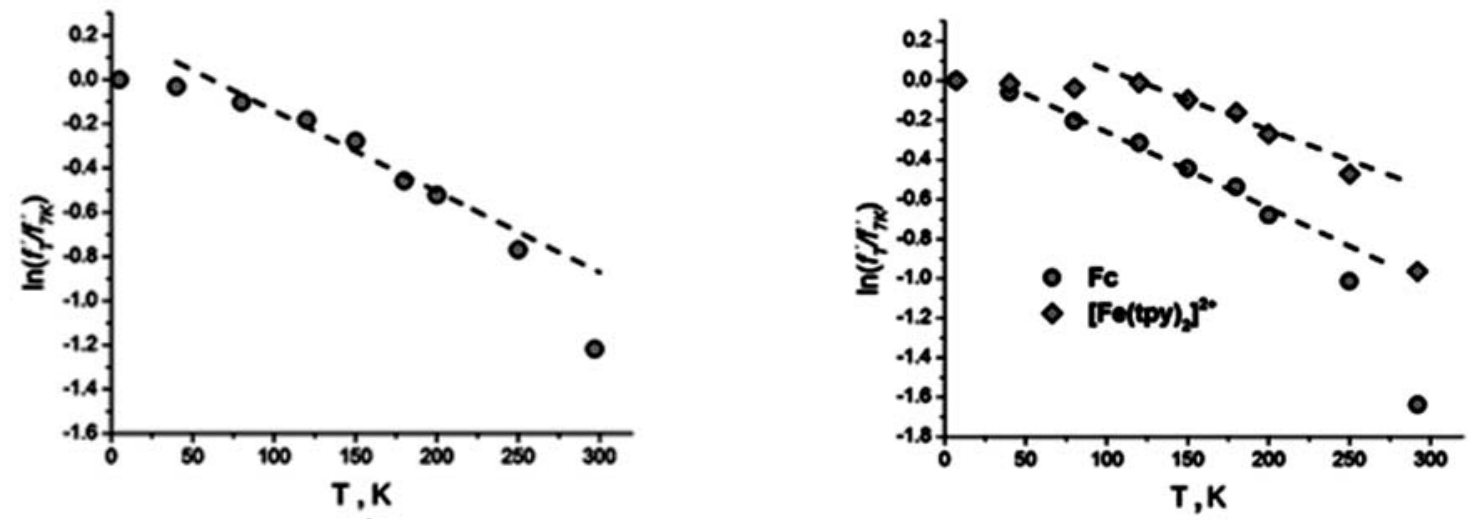

Figure 3. Plots of versus T for FcT (left) and FeFcT (right). Points between 80-200 K for Fc in FcT and FeFcT, but $120-200 \mathrm{~K}$ for $\left[\mathrm{Fe}(\mathrm{tpy})_{2}\right]^{2+}$ component were least-squares linearly fitted $\left(\mathrm{R}^{2}>0.99\right)$. 
The difference in Debye temperature for the two types of Fe nuclei in FeFcT results in a different ratio of $\mathrm{Fc} /\left[\mathrm{Fe}(\mathrm{tpy})_{2}\right]^{2+}$ peaks area at temperature variation (Figure 4). The plot of area ratio versus temperature can be seen in Figure 5, showing a smooth transition from $\mathrm{Fc} /\left[\mathrm{Fe}(\mathrm{tpy})_{2}\right]^{2+}=1$ at RT to the stoichiometrically expected $\mathrm{Fc} /\left[\mathrm{Fe}(\mathrm{tpy})_{2}\right]^{2+}=2$ at $7 \mathrm{~K}$.
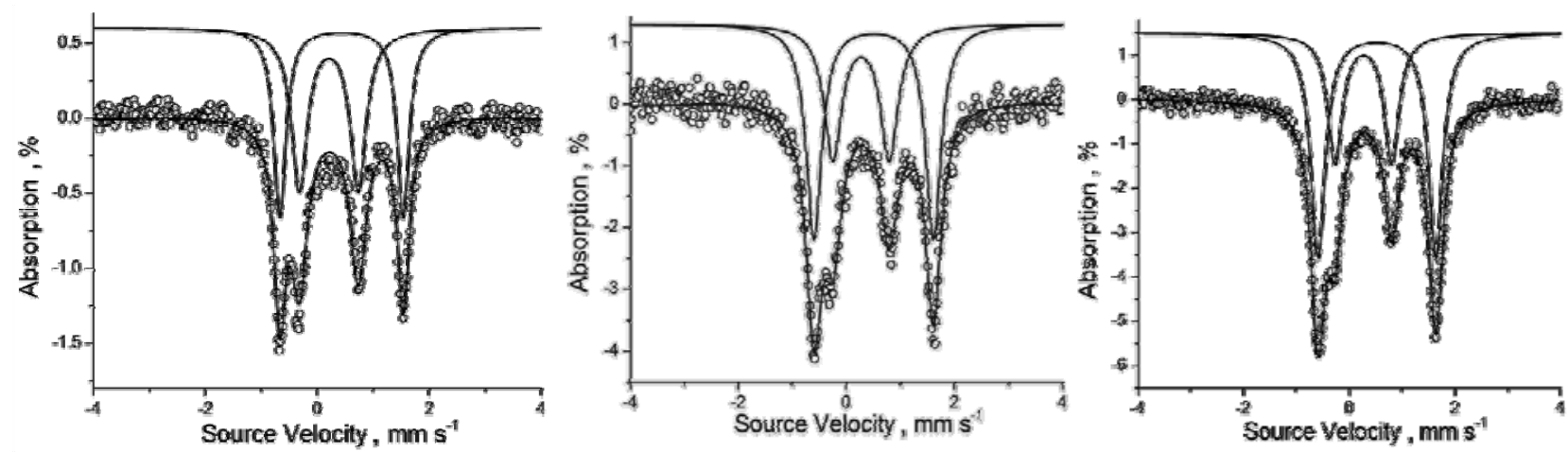

Figure 4. The experimental and fitted Mossbauer spectra for FeFcT at $293 \mathrm{~K}$ (left), $150 \mathrm{~K}$ (centre) and 7K (right).

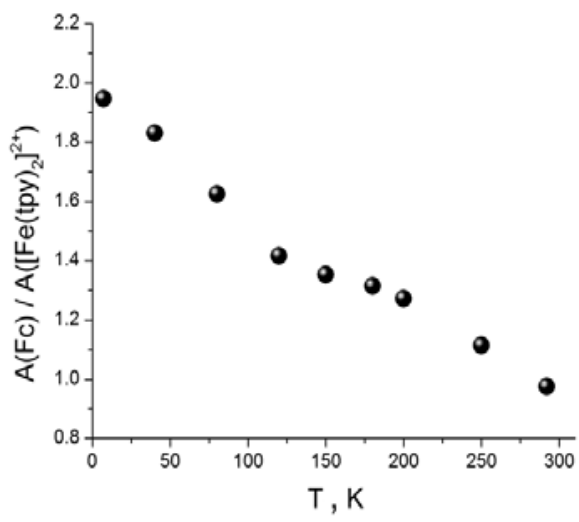

Figure 5. Plot of $\mathrm{A}(\mathrm{Fc}) / \mathrm{A}\left(\left[\mathrm{Fe}(\mathrm{tpy})_{2}\right]^{2+}\right)$ ratio versus $\mathrm{T}$ for FeFcT.

Another observed change in the spectra with the decrease of temperature is the increment of the IS (Figure 6). This is a result of the temperature dependent second-order Doppler shift contribution to the IS [11]. This effect was observed for all studied nuclei but while for the Fc the IS was increasing over the whole range of temperature, the $\left[\mathrm{Fe}(\mathrm{tpy})_{2}\right]^{2+} \mathrm{IS}$ almost stopped to increase at $150 \mathrm{~K}$. The IS increased with $0.1 \mathrm{~mm} / \mathrm{s}$ for Fc from both FcT and FeFcT, but with only $0.07 \mathrm{~mm} / \mathrm{s}$ for the $\left[\mathrm{Fe}(\mathrm{tpy})_{2}\right]^{2+}$ component.
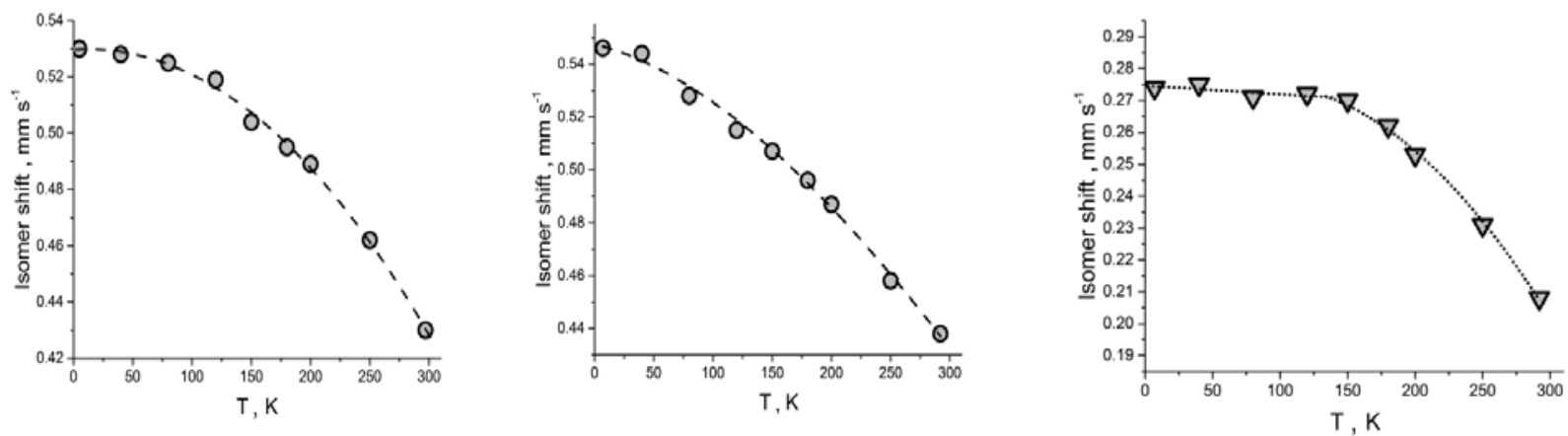

Figure 6. Plot of IS vs T for Fc from FcT (left), FeFcT (centre) and for $\left[\mathrm{Fe}(\mathrm{tpy})_{2}\right]^{2+}$ from FeFcT (right). 
The QS is more "inert" to the temperature variation (Figure 7) so that only a minor increment of $0.01 \mathrm{~mm} / \mathrm{s}$ was observed for $\mathrm{Fc}$ but a more pronounced effect of $0.04 \mathrm{~mm} / \mathrm{s}$ was noticed for $\left[\mathrm{Fe}(\mathrm{tpy})_{2}\right]^{2+}$. As result of these changes the two doublets are less overlapped at higher temperatures.
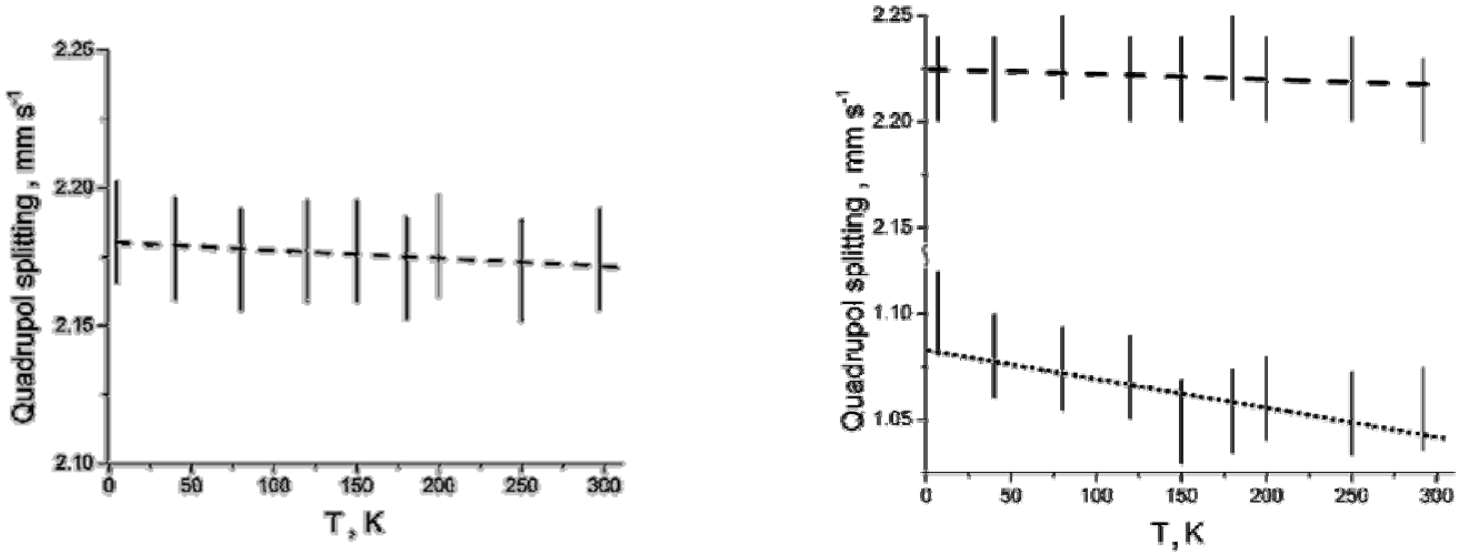

\section{Figure 7. Plot of QS vs T for FcT (left) and FeFcT (right). Dashed lines (- - -) show the trend for Fc components, while dotted line $(\cdots)$ - for $\left[\mathrm{Fe}(\mathrm{tpy})_{2}\right]^{2+}$ from FeFcT.}

\section{Conclusions}

The temperature dependence of the ${ }^{57} \mathrm{Fe}$ Mössbauer spectra for 1'-terpyridine ferrocenecarboxylic acid and [bis(1'-terpyridine ferrocenecarboxylic acid) $\mathrm{Fe}(\mathrm{II})]^{2+}$ was fully described. The Debye temperature was found to be $(184 \pm 14)$ and $(180 \pm 17) \mathrm{K}$ for ferrocene components of FCT and FeFcT and $=(218 \pm 15) \mathrm{K}$ for $\left[\left(\mathrm{Fe}(\mathrm{tpy})_{2}\right)\right]^{2+}$ unit, which supports the stronger metal-ligand binding and higher stability of the latter. Altogether, this example shows how the difference of Debye temperatures in polynuclear systems strongly affects the Mössbauer spectrum and should be taken in account when interpreting the experimental results.

\section{Acknowledgments}

I thank the national grant No. 11.817.08.22F for financial support and FP7-PEOPLE-2009-IRSES grant (246902) for funding to cover the exchange of researchers. I would like to thank as well my supervisors Prof. Constantin Turta from the Institute of Chemistry of ASM and Prof. Andrew Benniston from Newcastle University for the help in writing this paper.

\section{References}

1. Gütlich, P.; Bill, E.; Trautwein, A.X. Mössbauer Spectroscopy and Transition Metal Chemistry. Springer - Verlag: Berlin Heidelberg, 2011, XV, 569 p.

2. $\quad$ Pingheng, Z.; Desheng, X.; Haiqing, L.; Huigang, S. Temperature Dependence of the Mössbauer Effect on Prussian Blue Nanowires. Hyperfine Interactions, 2002, 142, pp. 601-606.

3. Benniston, A.C.; Sirbu, D.; Turta, C.; Probert, M.R.; Clegg, W. A simple method for desymmetrizing 1,1'-ferrocenedicarboxaldehyde. Tetrahedron Letters, 2014, 55 (28), pp. 3777-3780.

4. Korecz, L.; Abou, H.; Ortaggi, G.; Graziani, M.; Belluco, U.; Burger, K. The Mössbauer investigation of some derivatives of ferrocenes. Inorganica Chimica Acta, 1974, 9, pp. 209-212.

5. Clemance, M.C.; Roberts, R.M.G.; Silver, J. Mössbauer studies on ferrocene complexes VIII. Diacetyl ferrocenemetal halide complexes. Journal of Organometallic Chemistry, 1983, 247, pp. 219-222.

6. England, J.; Scarborough, C.C.; Weyhermüller, T.; Sproules, S.; Wieghardt, K. Electronic Structures of the Electron Transfer Series $\left[\mathrm{M}(\mathrm{bpy})_{3}\right]^{\mathrm{n}},\left[\mathrm{M}(\mathrm{tpy})_{2}\right]^{\mathrm{n}}$, and $\left[\mathrm{Fe}\left({ }^{\mathrm{t}} \mathrm{bpy}\right)_{3}\right]^{\mathrm{n}}(\mathrm{M}=\mathrm{Fe}, \mathrm{Ru} ; \mathrm{n}=3+, 2+, 1+, 0,1-)$ : A Mössbauer Spectroscopic and DFT Study. European Journal of Inorganic Chemistry, 2012, pp. 4605-4621.

7. Oshio, H.; Spiering, H.; Ksenofontov, V.; Renz, F.; Gutlich, P. Electronic Relaxation Phenomena Following ${ }^{57} \mathrm{Co}(\mathrm{EC}){ }^{57} \mathrm{Fe}$ Nuclear Decay in $\left[\mathrm{Mn}(\mathrm{II})(\text { terpy })_{2}\right]\left(\mathrm{ClO}_{4}\right)_{2} \cdot 1 / 2 \mathrm{H}_{2} \mathrm{O}$ and in the Spin Crossover Complexes $[\mathrm{Co}(\mathrm{II})$ (terpy) $)_{2} \mathrm{X}_{2} \cdot \mathrm{nH}_{2} \mathrm{O}\left(\mathrm{X}=\mathrm{Cl}\right.$ and $\left.\mathrm{ClO}_{4}\right)$ - A Mössbauer Emission Spectroscopic Study. Inorganic Chemistry, 2001, 40, pp. 1143-1150.

8. Hofmeier, H.; Schubert, U.S. Recent developments in the supramolecular chemistry of terpyridine-metal complexes. Chemical Society Reviews, 2004, 33, pp. 373-399.

9. Herber, R.H. Chemical Mössbauer Spectroscopy, Plenum Press: New York, 1984, pp. 199-216.

10. Ulrich, S.; Schubert, H.H.; Newkome G.R. Modern Terpyridine Chemistry. Wiley-VCH: Weinheim, 2006, pp. 37-68.

11. Pound R.V., Rebka G.A. Variation with Temperature of the Energy of Recoil-Free Gamma Rays from Solids. Physical Review Letters, 1960, 4 (6), pp. 274-275. 